\title{
Older Couples' Management of Multiple-Chronic Illnesses: Individual and Shared Perceptions and Coping in Type 2 Diabetes and Osteoarthritis
}

\author{
Jeremy B. Yorgason \\ Brigham Young University - Provo \\ Susanne Olsen Roper \\ Brigham Young University - Provo \\ Brandan Wheeler \\ Brigham Young University - Provo \\ Keillsterfthis and additional works at: https://scholarsarchive.byu.edu/facpub

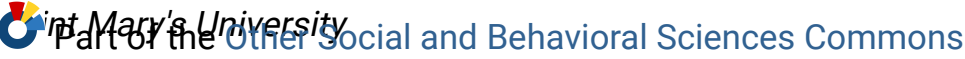

\section{Rebekah Byron}

\section{Drigimal/Prkatsiogation Citation}

Yorgason, J.B., Roper, S.O., Wheeler, B., Crane, K., Byron, R., Carpenter, L., Sandberg, J.G., Sheffield, R. \& Higley, D. (2010). Older couples' management of multiple chronic illnesses: See next page for additional authors

Individual and shared perceptions and coping in type 2 diabetes and osteoarthritis. Families,

Systems, and Health, 28(1), 30-47.

\section{BYU ScholarsArchive Citation}

Yorgason, Jeremy B.; Roper, Susanne Olsen; Wheeler, Brandan; Crane, Kristen; Byron, Rebekah; Carpenter, Leslie; Sandberg, Jonathan G.; Sheffield, Rachel; and Higley, Dawn, "Older Couples' Management of Multiple-Chronic Illnesses: Individual and Shared Perceptions and Coping in Type 2 Diabetes and Osteoarthritis" (2010). Faculty Publications. 4077.

https://scholarsarchive.byu.edu/facpub/4077

This Peer-Reviewed Article is brought to you for free and open access by BYU ScholarsArchive. It has been accepted for inclusion in Faculty Publications by an authorized administrator of BYU ScholarsArchive. For more information, please contact ellen_amatangelo@byu.edu. 


\section{Authors}

Jeremy B. Yorgason, Susanne Olsen Roper, Brandan Wheeler, Kristen Crane, Rebekah Byron, Leslie Carpenter, Jonathan G. Sandberg, Rachel Sheffield, and Dawn Higley 


\title{
Older Couples' Management of Multiple-Chronic Illnesses: Individual and Shared Perceptions and Coping in Type 2 Diabetes and Osteoarthritis
}

\author{
Jeremy B. Yorgason, PhD \\ Susanne Olsen Roper, PhD \\ BRANDAN WHEELER, BS \\ Kristen Crane, BS \\ Rebekah Byron, BS \\ Leslie CARPENTER \\ Jonathan G. Sandberg, PhD \\ RACHEL SHEFFIELD, MS \\ Dawn Higley, MS, RN, CDE
}

Using data from interviews with 28 older couples in which 1 spouse was diagnosed with diabetes and osteoarthritis, we examined illness perceptions and coping activities as they relate to illness management and relationship resilience. Qualitative analysis of interview transcripts revealed categories of data related to perceptions, coping, and cross category comparisons. Findings suggest that couples experience both negative and positive perceptions of their illnesses, indicating a balance between the reality of their illness challenges and an optimistic outlook of the future.

Jeremy B. Yorgason, PhD, Susanne Olsen Roper, $\mathrm{PhD}$, Brandan Wheeler, BS, Leslie Carpenter, and Jonathan G. Sandberg, PhD, School of Family Life, Brigham Young University; Kristen Crane, BS, Counseling and Human Services Department, St. Mary's University; Rebekah Byron, BS, School of Social Work, Indiana University; Rachel Sheffield, MS, The Heritage Foundation, Washington DC; and Dawn Higley, MS, RN, CDE, Intermountain Healthcare, Provo, UT.

Correspondence concerning this article should be addressed to Jeremy B. Yorgason, PhD, School of Family Life, Brigham Young University, 2079 JFSB, Provo, UT 84602. E-mail: jeremy_yorgason@byu.edu
Coping activities included a variety of tasks and were performed by individuals, by both spouses in a shared effort, and by individuals and shared couple efforts. Findings highlight the complexity of individual and shared couple illness perception and couple efforts in managing multiple-chronic illnesses.

Keywords: arthritis, chronic illness, diabetes, coping and adaptation, marital issues

$\mathrm{H}$ ealth problems within later life marriage have been investigated in a large number of published studies that have examined the effects of specific age-related health concerns, such as diabetes (Trief et al., 2003; Trief, Wade, Britton, \& Weinstock, 2002), arthritis (Zautra, Burleson, Matt, Roth, \& Burrows, 1994), osteoporosis (Roberto, Gold, \& Yorgason, 2004), and dementia (Baikie, 2002). Although findings from this literature are essential for persons managing specific health problems, little discussion has focused on interactions 
of health concerns within marriage when multiple illnesses occur simultaneously. This is an important gap in the literature as the majority $(69 \%)$ of older adults lives with multiple-chronic illnesses (Hoffman, Rice, \& Sung, 1996; Pastor, Makuc, Reuben, \& Zia, 2002). Bayliss, Steiner, Fernald, Crane, and Main (2003) addressed the question of how multiple-chronic illnesses affect people and found the presence of one chronic illness often necessitated lifestyle changes and/or medications that were incompatible with another chronic illness. The psychological stress of dealing with one chronic illness also sometimes aggravated another. As the repercussions of multiple illnesses might interact or be additive, the purpose of the present study was to examine marital relationships in later life couples in which one or both spouses were managing at least two specific chronic illnesses: Type 2 diabetes and osteoarthritis.

Type 2 diabetes and osteoarthritis are illnesses commonly experienced in later life. Diabetes mellitus is a prevalent and potentially devastating chronic illness affecting many older adults. It is the seventh leading cause of death among Americans (Trief et al., 2003) and affects one in five middle-aged and older American adults (Wray, Alwin, McCammon, Manning, \& Best, 2006). High and low amounts of blood glucose due to diabetes might cause severe or even life-threatening health problems, such as coronary artery disease, nerve damage, eye problems (e.g., blindness), kidney disease, or amputations (Sandberg, Trief, Greenberg, Graff, \& Weinstock, 2006). A second major chronic illness common to older adults is osteoarthritis; reports of arthritis among adults older than 65 years range from 36\% (Administration on Aging, 2003) to 50\% (Lawrence et al., 1998), with osteoarthritis being the most common form of arthritis in later life. Both Type 2 diabetes and osteoarthritis have implications for daily marital interactions. Specifically, diabetes management occurs on a daily basis, with regular monitoring of blood sugar levels as a central component of management. Osteoarthritis is associated with daily pain, flare-ups, and mobility restrictions.

\section{MARRIAGE AND CHRONIC ILLNESS}

Spouses are most often the first to provide day-to-day tangible assistance and support for ill partners (Revenson, 1994; Sandberg, 2006). Research clearly shows that how this support is given and received, as well as the marital interactions that accompany this support, impact both marital quality and health functioning. A review of marital interaction studies revealed "negative dimensions of marital functioning have indirect influences on health outcomes through depression and health habits, and direct influences on cardiovascular, endocrine, immune, neurosensory, and other physiological mechanisms" (Kiecolt-Glaser \& Newton, 2001, p. 472). Because marital functioning is clearly related to health outcomes (Coyne et al., 2001; Groth, Fehm-Wolfsdorf, \& Hahlweg, 2000 ), improving the quality of marriage has become a major public health concern (Kistenmacher \& Biglan, 2000).

Specific to diabetes, families with healthy interaction patterns are able to better manage this illness (Fisher et al., 1998). Furthermore, couples with higher quality relationships tend to act as a team in combating the effects of diabetes. At the same time, couples with lower quality relationships experience more conflict regarding the required illness management, resulting in poorer overall adjustment (Trief et al., 2002).

\section{FAMILY STRESS AND FAMILY RESILIENCY: GUIDING THEORETICAL FRAMEWORKS}

Factors that influence positive adjustment to multiple-chronic illnesses can be understood within the family stress and family resilience frameworks. From the family stress literature, the double $\mathrm{ABC}-\mathrm{X}$ 
model (McCubbin \& Patterson, 1982) suggests a focus on stressors, resources, perceptions, coping behaviors, and adaptation, which become important in understanding the extent of strain a couple faces and the ways they work toward adaptation. The timing of illness onset, duration, severity, and life threat of illness stressors influence the degree of strain on couples. Resources, such as education and income, are often moderators of stress effects on families. Illness perceptions form the appraisal of stressors, and resources provide the impetus for coping behavior.

\section{Illness Perceptions}

Perceptions of illness in later life can be linked to life experience, life expectations, and a desire to maintain independence. For some older adults, illness might be viewed as a part of the aging process. From a life course perspective, older adults often bring experience-colored perceptions of illness, sometimes resulting in less negative perceptions of health declines (see Löckenhoff \& Carstensen, 2007; Yorgason, Booth, \& Johnson, 2008). In contrast, perceptions of illness might be negative when experience goes against life expectations, such as when the future is ambiguous, demanding, or future losses are expected. In the case of rheumatoid arthritis, persons with this condition are most concerned about the future of the illness and the daily demands placed on the caregivers (Foxall, Kollasch, \& McDermott, 1989). Perceptions of maintaining independence also seem to be an important factor in whether illnesses are viewed negatively (Goodwin, 2000; Schiaffino \& Revenson, 1995).

In the context of Type 2 diabetes and osteoarthritis, both illnesses are age related and might be somewhat expected by older adults. This might be especially true for those with a family history of one or both illnesses. Some research has indicated that positive perceptions, despite illness, have been associated with better physical and mental health outcomes (Jang, Poon,
\& Martin, 2004). At the same time, illness symptoms, daily illness management, and dependence on others might result in negative health perceptions.

\section{Coping Strategies}

Coping with chronic illness has received considerable attention in the literature, with some focus on dyadic or couple coping (Bodenmann, 2005). In this study, dyadic coping is defined as ways that couples "share" the illness stressors and their resulting coping behaviors (Berg \& Upchurch, 2007). Berg, Meegan, and Deviney (1998) described three different ways that couples share illness such as (a) parallel individual, in which two spouses assess a health stressor differently and cope in different ways; (b) indirect relational, in which one spouse experiences a health stressor and the other spouse is influenced indirectly; and (c) shared relational, in which both spouses view a health problem as a shared stressor, and they cope jointly. Some research has indicated that couples who actively manage the diabetes together often report better disease management (Fisher et al., 1998; Gilden, Hendryx, Casia, \& Singh, 1989; Miller \& Brown, 2005; Trief et al., 2003). Conversely, negative spousal support or controlling attempts are often perceived by the patients as an infringement on their independence (Martire, Druley, Parris Stephens, \& Wojno, 2002; Revenson, Schiaffino, Majerovitz, \& Gibofsky, 1991).

\section{FAMILY RESILIENCE THEORY}

Walsh (2002) developed a framework intended to help family members focus on the positives of preexisting strengths and resiliency patterns. Her framework focuses on the use of (a) family belief systems, (b) organization patterns, and (c) communication processes. According to Walsh, belief systems consisted of making meaning of adversity, maintaining a positive outlook, and creating transcendence and spirituality. These concepts overlap with "percep- 
tions" in the family stress literature. Walsh's organizational patterns focused on the ability to be flexible and to adapt to challenges over time, the need for connections with others, a sense of teamwork and collaboration, and the use of social and/or economic resources. In essence, organizational patterns encompass the ways families are organized that allows them to tap into internal and external resources. Last, Walsh emphasized the importance of communication processes. These included clarity in giving and receiving messages, open emotional sharing among family members, and collaborative problem solving. The family resilience framework provides a lens through which couples' experiences can be interpreted and strengths despite adversity can be identified.

\section{RESEARCH QUESTIONS}

Drawing on the family stress framework, the current study explores couple-based perceptions of multiple-chronic illnesses, as well as coping activities performed to manage those illnesses. Although illness perceptions and illness-related coping activities have been identified in the literature, the present study extends current knowledge by examining shared couple perceptions and coping activities, as well as their interconnections. Furthermore, resilient couple processes are explored to better understand ways of managing multiple-chronic illnesses successfully.

\section{METHOD}

The current research involves qualitative data from a larger study (see Roper \& Yorgason, 2009, for details of the larger study) that was carried out using a mixed-methods approach to examine couples' management of diabetes and osteoarthritis. For this study, we use data from semistructured interviews that involved both spouses from each couple. Interviews focused on different aspects of the illnesses, couple challenges, and couple adaptation/resilience processes. Although a growing body of studies examines couple management or adjustment to specific ill- nesses, a qualitative approach was purposefully used in the present study, as the management of multiple-chronic illnesses is relatively unexplored. Consequently, we used a qualitative approach to explore couples' experiences and the meaning they attached to their experiences. Our study was theoretically informed by family stress and resiliency theory and followed a qualitative descriptive design, with grounded theory overtones (Sandelowski, 2000). That is, our basic purpose was to describe the experiences of couples with multiple-chronic illnesses in connection with already established theory, yet we used some methods from the grounded theory approach in our analysis.

The shared nature of illness experiences for married persons led us to interview spouses conjointly. Married persons managing chronic illness often share illness implications and management responsibilities (Berg \& Upchurch, 2007; Trief et al., 2003), which may be further amplified in later life (Carstensen, Isaacowitz, \& Charles, 1999). Due to the shared nature of illness experience among older married persons, we interviewed spouses conjointly with the specific aim of exploring illness management processes with both spouses present.

\section{Sample}

We recruited 28 married couples through a diabetes management clinic and diabetes education classes at two hospitals in a metropolitan county in a Western state. The two hospitals (two of five in the county) are among the largest in the area and serve patients of varying socioeconomic levels. Couples who met the following criteria were recruited: (a) one spouse experienced both diabetes and osteoarthritis, (b) the individual was married and older than age 59 years, and (c) both spouses were willing to participate in the study.

Of 19 eligible individuals identified through medical records to fit our criteria, eight agreed to participate in the study ( $42 \%$ response). Those who declined often 
stated they did not have time, thought the interviews were too personal, or were not interested in participating. Twenty additional couples were recruited from diabetes education classes and support groups provided by the same diabetes management clinics. Approximately $20 \%$ of eligible individuals at the diabetes classes/groups declined participation. The final sample included 28 couples (15 target wives; 13 target husbands). In eight couples both spouses had osteoarthritis and diabetes. For those couples, the spouse with more severe symptoms was chosen as the target (ill) spouse. Approval was granted to carry out the study by the affiliated hospital and university Institutional Review Boards for research involving human subjects.

The average couple in our sample consisted of a 68 -year-old $(S D=7.34$, range $=$ 58-85) White woman (the target spouse) who had been experiencing osteoarthritis for 15 years $(S D=12.97$, range $=2-50$ ) and diabetes for 10 years $(S D=9.99$, range $=1-35$ years) and her 68-year-old $(S D=8.18$, range $=56-82)$ White caregiver husband. On a 4-point Likert-type scale ranging from 1 (not bad at all) to 4 (really bad), the typical ill spouse rated her osteoarthritis severity as 3 (bad) and her diabetes severity as 2 (not too bad; on the same scale). The typical wife reported having five illnesses, whereas the typical husband reported having three illnesses. The average couple had been married 42 years $(S D$ 13.53, range $=3-66)$. Using a 10 -item quantitative measure of marital happiness (for scale properties and individual item descriptions see Johnson, White, Edwards, \& Booth, 1986), husbands and wives in the sample reported that they were fairly happy, on average, in their marriage (husband, $M=1.62, S D=0.34$; wife, $M=1.53$, $S D=0.45)$, on a scale consisting of responses including 0 (not too happy), 1 (pretty happy), and 2 (very happy; see Table 1, for more detailed information about illness severity).

\section{Interview Procedures}

Four members of our research team conducted and transcribed the couple interviews and assisted with the data analysis. Prior to collecting data for this study, these team members were trained in research with human subjects, in qualitative research methods, and carried out a complete pilot study.

In collecting data, team members visited couples in their homes. After couples signed an informed consent to participate in the research and completed a baseline survey, team members interviewed spouses together using a semistructured format. Team members carried out interviews with both spouses present to capture shared meaning in couples' experiences related to health.

The interviews consisted of three major sections. The first section established the story of the individual's health problems, including first notice of symptoms, severity of their health problems, medical interventions used, and so forth. The second section explored belief systems and meanings to determine how couples perceived and responded to the challenges of diabetes and osteoarthritis. Examples of questions included, "What helps you make sense of your health problems?" and "How have your health problems influenced your marital relationship?" The last section explored the couples' resilience to the health challenges, asking questions such as, "What has helped you as a couple to withstand or overcome the difficulties associated with diabetes/arthritis?" Interviews lasted approximately one hour for each couple.

Additional data sources included field notes and "member checks." Field notes were kept by the interviewers to describe participants and their contexts. Member checks involved sending a brief (one to two page) summary of an interview to the couples that participated, with the invitation to contact the researchers if participants had any comments, changes, or additions to the summary. Of the 28 couples that were sent sum- 
maries, seven participants verified the major themes from their interviews.

\section{Analysis}

Two members of the research team began analyzing transcripts of completed interviews while they continued to conduct interviews with subsequent participants. Although the data gathering and analysis proceeded concurrently, we did not use any theoretical sampling procedures to adjust our interviewing process. Interviews continued until saturation of categories was achieved.

We used a qualitative content analysis methodological approach (Sandelowski, 2000) to code, analyze, and interpret themes from interview transcripts, interviewer field notes, and member check responses. We used family adaptation and resilience concepts as sensitizing concepts to guide the analysis (Gilgun, 2005). The principal analytic tool was constant comparison across subjects in which incidents and phenomena were compared for similarities and differences in properties, dimensions, and processes (Merriam, 1998). We first performed open coding, in which two team members identified broad groupings of illness perception and coping in the transcripts (Corbin \& Strauss, 1990; Daly, 2007). These groupings were then imported into N-Vivo 7 software to help organize the data (QSR International, 2006).

In the second phase, axial coding, we strengthened conceptual links within and across initial codes to form broader and more theoretically dense categories and revised hypotheses (Corbin \& Strauss, 1990; Geertz, 1988). Two team members worked together to make refinements to the illness perceptions themes until consensus was reached. The same procedure was carried out by two other team members examining coping. Throughout the analysis process, we kept an audit trail, detailing how we derived conceptualizations of themes and categories (Gilgun, 2005). Field notes and member checks also were analyzed in connection with the interview transcripts.

Team members analyzed the coping data twice: once to explore transcript content, and once to explore individual versus shared couple coping efforts. As an example of the content analysis, the initial groupings of quotations regarding coping yielded 28 different codes. Team members identified exceptions and possible redundancies in the initial coding criteria and collaboratively worked to regroup the original 28 codes into four more theoretically dense groupings representing the coping activities. The names for these groupings were based on relevant literature and highlight key themes in illness management among older adults. This is considered to be one type of theoretical sampling, in which labels for data groupings are informed by previous analytical findings (Charmaz, 1983; Corbin \& Strauss, 1990). The newly labeled codes provided a more complete or "thicker" description of the couples' illness perceptions and coping (Geertz, 1988).

We repeated this process until theoretical saturation was reached; that is, until additional analysis revealed no new redundancies or exceptions that added to the richness of the description. After we completed this process for the illness perceptions and coping groupings of data, the two groups of our team members came together and discussed connections between perceptions and coping themes. Two of the team members then analyzed the coping data to explore individual versus shared coping efforts.

\section{RESULTS}

The qualitative analysis revealed four categories within the theme of illness perceptions. They included: (a) life's lessons applied, (b) negative perceptions of illness, (c) positive perceptions of illness, and (d) "dealing" with diabetes and osteoarthritis.

\section{Illness Perceptions}

\section{Life's Lessons Applied}

Couples' perceptions included lessons about life that were applied to managing 
Table 1

Arthritis/Diabetes Severity and Arthritis/Diabetes Severity and Individual and Shared Coping Efforts in Medical, Daily Routine, Diet, Exercise, and Education Activities

\begin{tabular}{|c|c|c|c|}
\hline Couple & Arthritis severity & Diabetes severity & Medical \\
\hline $1^{\mathrm{a}}$ & $\mathrm{Bad}$ & Not too bad & Individual/shared \\
\hline 2 & Not too bad & Not too bad & Individual \\
\hline 3 & Not too bad & Bad & \\
\hline 4 & Bad & Really bad & \\
\hline 5 & Really bad & Not too bad & Individual/shared \\
\hline 6 & Not too bad & Not too bad & Individual \\
\hline $7^{\mathrm{a}}$ & $B a d$ & Bad & Individual \\
\hline 8 & Not too bad & Not too bad & Individual/shared \\
\hline 9 & Bad & Really bad & Individual \\
\hline 10 & Bad & Not too bad & Individual \\
\hline 11 & Bad & Bad & Individual \\
\hline 12 & Bad & Not too bad & Shared \\
\hline 13 & Not too bad & Not too bad & Individual \\
\hline 14 & Not too bad & Not too bad & Individual \\
\hline $15^{\mathrm{a}}$ & Bad & Bad & \\
\hline $16^{\mathrm{a}}$ & Bad & $B a d$ & Shared \\
\hline 17 & Missing & Bad & \\
\hline 18 & Really bad & Really bad & \\
\hline 19 & Bad & Bad & Individual/shared \\
\hline $20^{\mathrm{a}}$ & Not bad at all & Bad & Individual/shared \\
\hline $21^{\mathrm{a}, \mathrm{b}}$ & Not bad at all & Really bad & \\
\hline $22^{\mathrm{a}}$ & Not too bad & Not bad at all & Individual \\
\hline 23 & Bad & $\mathrm{Bad}$ & \\
\hline 24 & Not too bad & Not too bad & Individual/shared \\
\hline 25 & Really bad & Not too bad & Individual \\
\hline $26^{\mathrm{a}}$ & Bad & Not too bad & Shared \\
\hline 27 & Not too bad & $B a d$ & Shared \\
\hline 28 & Not too bad & Not too bad & \\
\hline \multicolumn{4}{|l|}{ Totals } \\
\hline Individual & & & 10 \\
\hline Shared & & & 4 \\
\hline Both & & & 6 \\
\hline
\end{tabular}

Note. Diabetes and arthritis severity values were measured on a 4-point Likert-type scale ranging from 1 (not bad at all), 2 (not too bad), 3 (bad), to 4 (really bad). Individual = identifiable individual efforts in the interview in a given area of illness coping; shared = identifiable shared couple efforts in the interview in a given area of illness coping. Both $=$ where both identifiable individual and identifiable shared couple efforts were evident in the interview in a given area of illness coping.

${ }^{a}$ Indicates couples in which both spouses have both diabetes and osteoarthritis. ${ }^{\mathrm{b}}$ No data from Couple 21 were coded according to the five types of coping in this table.

diabetes and/or osteoarthritis. Of the 28 couples in the study, many discussed the need to persevere (22), the importance of staying positive (19), the view that their situation could be worse (17), that they were grateful (13), and continued to have faith (21). Such attitudes appeared to be general life philosophies that had been in place and were now being applied to the illnesses, rather than attitudes that were developed after individuals had been diagnosed with diabetes and osteoarthritis. For example, one wife whose husband had diabetes and osteoarthritis stated:

It must have something to do with the way that I was brought up, but you don't just mire in self-pity. You can't do that 


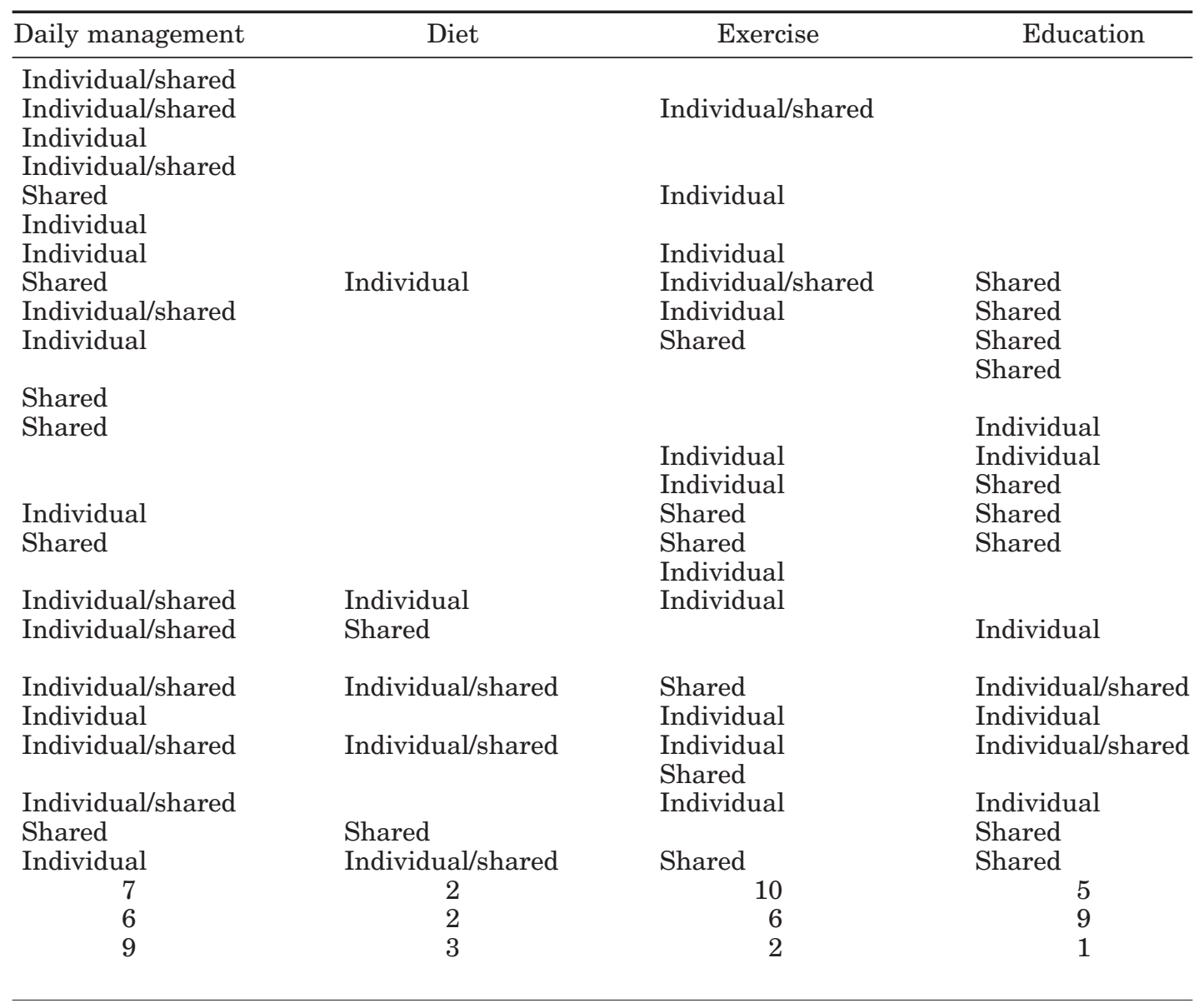

.. . life is for living. I just have this really strong feeling about it, and I'm not going to bask in self-pity.

A wife with both illnesses shared her perspective:

I've lived with pain all my life, so I try not to pay any attention to it. There's more in life than just pain. I mean you get up in the morning and you can see the sun and the beautiful world and hear the birds sing . . . How could I ask for any more than that?

\section{New Perceptions in Response to Illness: Negatives}

Many couples (24) expressed frustration, feeling overwhelmed, annoyed, or depressed in response to managing Type 2 diabetes and osteoarthritis. For example, 
one wife with diabetes and osteoarthritis stated,

It's so frustrating (getting choked up) 'cause I want to do so much, you know? I can't keep the house up the way I used to, I mean, there's a lot of things that's not being done like it used to be ... I'll probably get used to it . . . but right now, it's so new and ... I can't really quite handle it.

Some couples also expressed uncertainty about the future or how to manage their illnesses (18), fear (9), anger and bitterness (3), and shock (3), indicating that despite their best efforts to manage their illnesses, they were still stressed by them. One wife with diabetes and osteoarthritis posed the question of "why me?" stating that she got "right down bitter" about her illnesses. Another wife with both illnesses stated, "I'm still terrified of it. I was terrified of it when I was a child because when I was 15 , my father died . . . with diabetes. And so it's very terrifying to me."

Others were less upset and described their diabetes and osteoarthritis less negatively. For example, one wife with both illnesses stated, "That's what diabetes is to me: a big, fat nuisance."

Negative perceptions might relate to inactivity and limited proactive diet and exercise behavior. One male participant stated,

I feel a lot of guilt because I don't exercise like I'd like to, I don't eat as careful as I'd like to. I feel like it consumes me all the time that I have to eat just right, and yet I'm never happy with it.

For another couple, seven references to feeling uncertain about their future were made during their interview, with no references to any kind of exercise or diet management. Another couple made eight references to uncertainty with only one reference to controlling diet and exercise. These couples represent the minority in the sample, yet they also illustrate an im- portant connection between negative perceptions of their illnesses and illness management activities.

\section{New Perceptions in Response to Illness: Positives}

Despite their difficulties and frustrations, all 28 couples mentioned at least one positive perception regarding their management of the illnesses. The ones most commonly expressed included the importance of being proactive in managing their illnesses (20), the view that things could be worse (17), accepting the illnesses (17), and that it is important to stay positive (19) and not worry (5). Regarding being proactive, one wife with diabetes and osteoarthritis reported, "[managing the illnesses] was hard at times, but you just do what you have to do. You can either sit and cry about it, or accept it and move on." A husband with both illnesses stated, "I just figured that I could put [up] with aches and pains, I could put up with diabetes. Whatever challenge is thrown to me, I'll overcome it, put up with it and deal with it." One couple summarized it this way:

Wife: Well, we want to live, so we just go ahead and live! There's no big end just because I have diabetes.

Husband: I'd rather be in control of my life than have my illnesses be in control of my life.

Many couples also described how they had grown as a result of their health problems. Almost half (12) of the couples discussed how through their illness experience they had developed personal qualities such as empathy, patience, understanding, flexibility, compassion, humility, kindness, courage, and tolerance. Among these, patience and understanding were most often mentioned. Part of an interview illustrated this theme:

Interviewer: What lessons do you think you've learned from your experiences with diabetes and arthritis? 
Wife: Well, I feel like I've learned more tolerance for other people that have problems, not just diabetes, [but] all kinds of problems. I think you understand better that other people are suffering and that, yeah, it's hard!

Husband: Well, I think it's probably more than tolerance, it's probably compassion you know ... you really feel for people ... you have empathy for them.

\section{Dealing With Diabetes and Osteoarthritis}

In what appeared to be a compromise between positive and negative perceptions, couples reported to simply deal with their situation. Specifically, 19 couples reported learning to deal with their health problems, and 15 suggested that the illnesses were "not an issue." One couple illustrated the connection between recognizing illness stressors and keeping a positive outlook:

I would just probably just say you can do this; it isn't insurmountable. You can make these adjustments in your life, and it doesn't mean that you're going to like them, it doesn't mean that they are going to be easy, or convenient ... but you can do it . . . and a lot of it is your attitude on whether you can or can't.

A husband whose wife had diabetes and osteoarthritis summarized this perspective saying, "You just gotta ... learn how to deal with it." Another respondent, a wife with diabetes and osteoarthritis stated,

You got a disease .... You just have to deal with it. If you just go to bed and forget about life, then you'll turn into a vegetable and you'll die, and I'm not ready to die right now.

This perspective, of seeing multiplechronic health problems as situations that are accepted and dealt with but are not a major problem, is interesting given the complex picture of coping activities reported. Specifically, if couples had been healthier, they would have been less likely to perform the numerous daily health management activities they described.

\section{Coping}

Two separate analyses of coping were performed. First, we explored the coping activities identified by participants, and then we explored patterns of coping on an individual or shared, couple basis. In the first analysis, four themes regarding the types of activities couples used to cope with and manage their diabetes and osteoarthritis emerged. Activities included (a) medical activities, (b) exercise and diet, (c) daily activities, and (d) educational activities. Regarding medical activities, nearly all of the couples (25) talked about testing blood sugar and taking medications. More than half of the couples (15) described the importance of their exercise and diet habits. Health habits were not always easily performed, as evidenced by comments of a wife of an ill husband:

We're just trying to control [the diabetes], trying to exercise, but that's where you get the problems with arthritis and diabetes. The best thing for diabetes is exercise. What hurts the worst ... when you have arthritis is exercise.... So, the two so often go together but they work against one another.

Many couples (20) discussed the daily activities associated with managing their illnesses. They specifically referred to making adjustments or changes in their lifestyle (e.g., spending more time doing illness-related activities) and following an adjusted, health-focused routine. Last, many couples (21) reported attending diabetes education classes offered in their community or seeking out information on the Internet or in books. That many attended classes was not surprising, as recruiting efforts were made through these classes. Still, gaining knowledge, especially through classes, appeared to empower couples and help them cope with the added 
responsibilities related to managing the diseases.

\section{Individual Versus Couple Coping}

Because we were able to interview married couples, a contribution of this study is the ability to explore if and how couples coped with diabetes and osteoarthritis together. Shared coping was the focus of the second analysis of coping activities. In this regard, some couples seemed to handle problems as individuals, some appeared to cope in a fully shared nature, and others had a mix of individual and shared coping activities (see Table 1 for a summary of these analyses). Often, an emphasis on teamwork and sharing the responsibility of illness became apparent as a way to positively cope. This included shared decision making about meals, exercise, and overall schedule. Couples also solved problems in collaborative ways to make necessary changes to cope more effectively with diabetes and osteoarthritis.

\section{Medical Activities}

Transcripts reflected that 10 couples used an individual approach, four couples reported a fully shared approach, and six couples reported a "mixed" individual and shared approach to managing medical activities. Those couples with an individual approach did not mention their well spouses helping out with any aspect of their medical activities.

For others (10), some involvement in medical activities was either described or it was apparent from the spouses' interaction in the interview that the well spouse was involved to some degree. This involvement ranged from well spouses getting out all the pills or helping the ill spouse get around if they were having a bout with arthritis, to spouses simply knowing a lot about the management of the diseases. For example, one husband reported how he cared for his spouse, "I can help her get a heating pad if I need to, maybe talk her into taking some ibuprofen." In contrast, another husband was very knowledgeable about all his wife's medications and helped administer them, as well: "She was taking one time 3,200 $\mathrm{mg}$ of Motrin a day ... that's a lot .... She has to take Lantus and also the Novolog ... I give [her] a Novolog shot. Usually, she takes her blood."

\section{Diet and Exercise}

When individual versus shared diet and exercise coping activities were examined, diverse approaches were identified. Five couples reported managing a diet (including eating or avoiding certain foods) together. In the case of three of these couples, although diet management was performed at the couple level, individuals also took responsibility for certain diet dimensions. In two cases, individual responsibility for diet was mentioned, with no mention of shared efforts. A similar pattern was found with regard to exercising, in that some exercised alone (10), some couples exercised together (6), and some exercised both as individuals and couples (2). One husband stated, "We go out down on the trail here and we get in anywhere between 2 and 3 miles there just walking, and she's outdoing me now." It is interesting to note that five of the six references to exercising together involved walking. In contrast, reports of individual exercising involved activities such as walking, swimming, or aerobics, as well as activities to keep joints moving. For example, one participant with osteoarthritis stated, "[When] I get up in the morning my hands hurt so much I can't even grip them tight and by the end of the day I'm okay because I've been working with them all day long."

\section{Daily Activities}

Three patterns emerging from the data reflected how couples participated in daily routines or activities. These patterns ranged from total responsibility for health routines by the spouse with diabetes and osteoarthritis, to collaboration between spouses in health-related daily activities. For exam- 
ple, for seven couples, only the spouse with osteoarthritis and diabetes was involved in the daily health routines. For these couples, the ill spouse took total responsibility for taking medicine, monitoring blood sugar, and exercising, and each spouse seemed to have their own schedule and routine. For nine couples, the ill spouse took major responsibility for health routines such as taking medicine, but the well spouse provided help in the form of physical assistance or reminders when needed. One wife described taking her medicine on her own, but bemoaned, "It's just when I get to the point where I'm so stiff I can't even move that I'm in big trouble. He has to help me get up, you know, and stand up. I mean, it's horrible."

Finally, six couples appeared to be fully collaborative in managing the diseases. For example, one wife said,

We set a bowl out, and he puts the pills in there in the morning, now if he sees the pills in there, he knows he's forgotten to take them. And we tried to maybe start with the nighttime because sometimes he forgets.

Other couples did not specifically describe disease management but in talking about what they did, they framed the disease experience as being shared. One well husband stated, "We have these ups and downs," while another said, "So we are taking better care of ourselves now and I think that is gonna help the quality of our lives that's remaining."

\section{Education Activities}

Although only five participants reported either attending classes or seeking out information without their spouse, 11 participants and their spouses reported gaining education about their health problems as a shared venture. One wife whose husband had diabetes and osteoarthritis reported, "We've taken the classes. [My husband] couldn't hear all of it, but he went with me, and they're great. I mean if you do all the things they tell you to do, you'll do great." For another couple in which the wife had both illnesses, the husband was not able to attend the diabetes class due to work, but they reported looking at websites together to learn more about diabetes. In summary, educational opportunities were typically sought out by research participants, and often these efforts were accomplished at the couple level.

\section{Explicit Individual and Shared Activities}

In addition to couple reports of doing individual versus shared activities, some couples explicitly stated whether they worked together or individually in managing diabetes and osteoarthritis. The following comment reflects a relationship focused on teamwork:

Husband: I would best describe it by a shared responsibility. We do it together!

Wife: He takes very good care of me.

Husband: She'll test and we'll kind of go through well how much insulin do I take and this type of thing. She's really learned pretty good to calculate it, guess, whatever you want to call it, pretty close to how much insulin to take which has helped. It's just nice to have the support of each other, that's the thing.

For another couple, only the spouse with diabetes and osteoarthritis managed the illnesses, illustrating explicit individual efforts. The couple did not seem to view this individualism negatively:

Interviewer: Do you find that you work together on this?

Husband: No. She does her thing and I do my thing. ... She's a big girl; she can take care of herself.

Interviewer: So you don't have to remind her or anything?

Wife and Husband together: No, no. 
Although this couple did not see teamwork as a necessary component to coping, comments from other couples illustrated how important this shared responsibility and support meant to them and their marriage:

Wife: It all boils down to support.

Husband: Yeah, being married means supporting each other in whatever, even though over the years you fight and argue, disagree (laughs). But it always passes over, that's the good thing in a good marriage. I mean a good marriage doesn't mean that people are happy and carefree all the time. A good marriage means that you're able to cope with what comes along with each other, you know. And that's the only way you can deal with any kind of sickness or disease, or whatever. I mean, anybody can be stricken with something anytime.

Data from researcher field notes and member checks provided additional support for individual, shared, and mixedindividual/shared coping. Field notes indicated that some interviews involved a shared discussion of the illnesses (11), some were more individually focused (6), and some involved a mix of individual and shared interest (3). Within member checks several couples emphasized togetherness and a shared effort (6), whereas one had an individual focus.

In summary, participants held both positive and negative perceptions about their own or their spouses' diabetes and osteoarthritis. Most made considerable efforts to cope with and manage both illnesses, with some activities occurring at the individual level and others occurring at the couple level. All of these data points seem to indicate that through individual and shared efforts, each couple developed their own pattern of dealing with the health challenges they faced.

\section{DISCUSSION}

The trend that most adults older than 65 face multiple-chronic illnesses provides a strong motivation for research to consider combined effects of those illnesses. This study examined shared illness perceptions and coping described in interviews with 28 couples in which one spouse had Type 2 diabetes and osteoarthritis. Specifically, the purpose of the study was to explore couple perceptions and coping behaviors, as well as ways that perceptions and coping were intertwined.

Results indicated a mix of negative and positive illness perceptions: Most couples learned to accept and manage health problems while maintaining a positive outlook on life. Coping efforts included efforts by individuals and couples to seek medical help, exercise and manage their diets, adjust daily activities and routines, and seek education. Supporting findings from previous research (Berg et al., 1998), couples described their coping activities as either individual, shared, or a mix of individual and shared efforts. Healthy management of the illnesses was identified in couples who used a proactive approach to coping, whether it was individual, shared, or a mix of both. Couples who might not have managed their health as well spoke of activities they wanted to do or knew they should be doing, but no evidence was provided that they were doing those things.

\section{Perceptions}

Illness perceptions were discussed by both target and supporting spouses. Interviews were structured so that each spouse could participate and share his or her opinions about their situations. That little disagreement was identified in the interviews suggests somewhat of a consensus between spouses about their reports. Lifelong lessons used by couples as a lens to view their current situations is supported by the literature. Specifically, Roberto, Gigliotti, and Husser (2005) indicated that women in their study used "lifelong philosophies" 
that guided both the behavioral and psychological strategies they used to cope successfully with multiple health conditions (p. 682). Furthermore, the positive perceptions and acceptance reported by participants in this study are similar to findings regarding the perceptions of individuals suffering from serious diseases (DenzPenhey \& Murdoch, 2008).

Negative perceptions reported by couples indicated that managing multiple chronic illnesses can be stressful, even after an average of 10 (Type 2 diabetes) to 15 (osteoarthritis) years post diagnosis. This is not surprising, given that most couples in the current sample reported to have multiple-chronic illnesses beyond the diabetes and osteoarthritis. Reports of fear, frustrations, and uncertainty might be linked to the ambiguity of what the future holds for participants and their illnesses. This is supported in the literature in that ambiguous losses can be some of the most stressful ones that families face (Boss, 2006; Foxall et al., 1989).

\section{Coping}

Shared coping was manifest in that primarily, spouses gave instrumental, problem-focused support. This finding supports the idea that support in the marital relationship when illness is involved can be associated with better health (Trief et al., 2003). Reliance on problem-focused coping was not surprising, given that problem-focused coping is helpful when activities influence health outcomes, whereas emotion-focused coping is often more helpful in situations outside of personal control (see Foxall et al., 1989). In other words, couples in the present study coped in a way that suggests they see some personal control over their situation.

Roberto and colleagues (2005) indicated that distracting activities are often helpful in getting peoples' minds off of their illnesses. In this study some distracting activities were reported, yet they were bal- anced with an increase in activities related to illness management. Perhaps activities not associated with illness provide emotional respite from illness management when care activities are commonplace. The development of new health-related routines, often involving spouses, also seems related to healthy adaptation (Denham, Manoogian, \& Schuster, 2007).

\section{Connecting Perceptions and Coping}

In making connections between illness perceptions and coping behavior, a portrait of healthy illness management emerges. Similar to findings from other studies (e.g., Yorgason, Piercy, \& Piercy, 2007), the combination of negative and positive perceptions (illustrated in by statements of "dealing with the illnesses") suggest a healthy adaptation to illness, and evidence of aging well (see Poon, Gueldner, \& Sprouse, 2003). This way of adapting is especially relevant in the current study, where perceptions were often positive, despite reports that coping activities were numerous in virtually every couple situation. Perhaps this type of balanced adaptation is supported when illness is viewed as part of the aging process (Jang et al., 2004; Löckenhoff \& Carstensen, 2007; Yorgason et al., 2008).

That coping was often shared is not surprising, and an integration of individual and shared behaviors may be indicative of a healthy balance in functioning. Studies have identified unhealthy approaches. For example, gaining knowledge about an illness to provide support to an ill spouse can be done in a controlling or supportive way (Peyrot, McMurry, \& Hedges, 1988). Revenson, Schiaffino, Majerovitz, and Gibofsky (1991) described this continuum of supportive behavior as the double-edged sword of social support. Revenson and colleagues reported that positive support predicted lower depression, and problematic support predicted higher depression among rheumatoid arthritis patients. Trief and colleagues (2003) suggested that there is a fine line between a helpful reminder of 
health treatments for diabetes and nagging or pushing a partner to pursue treatment. Also, Kuijer et al. (2000) recommended an appropriate balance in which the patient copes well on their own and the spouse provides support of that coping.

Various approaches to coping including individual, shared, and mixed (individual and shared) appeared to be successful for participants in this study, depending on the couples' situation. As seen in Table 1, illness education and daily management were more often shared. Research has indicated that the amount of "we-talk" (evidencing shared ownership of illness) used by caregiver spouses is related to better health outcomes (Rohrbaugh, Mehl, Shoham, Reilly, \& Ewy, 2008). Still, variation in couple responses to later life chronic illness has been identified in other samples (see Berg et al., 1998). Additional study is needed to understand couple dynamics prior to illness onset and how those change with illness management, and the degree to which involvement by spouses is driven by illness severity and caregiving demands.

\section{Limitations and Implications}

The sample was recruited through hospital medical records and diabetes education classes conducted at an area hospital, which might limit transferability of the findings. Specifically, findings might not be representative of couples in which spouses do not receive regular medical services, are less concerned about managing their illnesses, or perceive themselves as having little time to participate in health-related activities. In addition, as most couples in the current sample reported to be fairly happy in their marriage, and both spouses had to be willing to participate to be included in the study, couples experiencing lower marital happiness may have been less inclined to participate in the study. Such individuals might be different from those in the sample in how they perceive their illnesses as well as in their methods of coping. Information about their perceptions and coping could greatly enlarge our understanding of couple adaptation.

Interviews in the current study were carried out with both spouses present, which could influence reports of illness perceptions and coping. Even though interviewers encouraged both spouses to participate evenly in the interviews because couples were interviewed together, the discussion might have been dominated by one spouse. Furthermore, some spouses might have qualified their responses or not responded because their spouse and/or the interviewer were present and they felt they should respond a certain way. For example, research on couple relationships where one spouse is ill suggests that well spouses sometimes withhold thoughts and opinions from the ill spouse in attempts to buffer them from further strain, which may have occurred in the current study (Manne et al., 2007). Consequently, it is possible that spouses might not have accurately represented their actual experience in the interviews (Funk \& Stajduhar, 2009). Future research that involves observing couples in their natural settings, longitudinal research, or studies that include both couple and individual interviews could provide information beyond couple reports (Funk \& Stajduhar, 2009; Sandberg et al., 2006).

In eight couples in our sample both spouses had osteoarthritis and diabetes. It is possible that couple dynamics might be different in couples where only one spouse is managing diabetes and osteoarthritis. Follow-up analyses (not shown) indicated no differences in patterns of coping, perception, or individual versus shared coping for the current sample. One possible explanation for this lack of differences is that in all eight cases where both spouses had both diabetes and osteoarthritis, one spouse clearly experienced greater severity of the illnesses. In samples where illness severity is similar for both spouses, perceptions and coping efforts may operate differently. 
We did not determine if coping and perceptions differed depending on the gender of the target spouse, nor did we take into account how long the target spouse had been diagnosed with the multiple-chronic illnesses. Research is needed regarding gender differences as well as how the time since diagnosis is related to perceptions and coping in managing comorbid illnesses. Also, longitudinal research is needed to better understand the challenges associated with illness in later life, and how older adults manage after years of illness. This research will be especially relevant as the population ages and in relation to chronic illnesses that become progressively more severe with time.

Findings from this study have important implications for various types of medical, mental health, and other service practitioners. First, professionals working in diabetes clinics, such as doctors and nurses, should be aware of ways that diabetes management may be hampered by comorbid health conditions such as osteoarthritis. Although diabetes and osteoarthritis were the target illnesses in the current study, other illnesses may influence each other in similar ways. Medical and mental health professionals may further benefit from understanding the various ways that their patients perceive and cope with their health problems, including the often interconnected nature of illness management by married persons.

In conclusion, findings from the present study provide an initial window into the lives of later life couples managing multiple chronic illnesses. Furthermore, the combined nature of chronic illnesses in later life is illustrated in two age-related chronic illnesses that affect many couples. Results suggest that couples experience both negative and positive perceptions of their illnesses, indicating a balance between the reality of their illness challenges and an optimistic outlook of the future. The complexity and shared nature of illness perceptions and coping activities among later life spouses provides an important contribution to the literature. Professionals who work with couples facing multiplechronic illnesses should be aware of individual and shared perception and coping efforts as well as indicators of aging well.

\section{REFERENCES}

Administration on Aging. (2003). A profile of older Americans: 2003. Washington, DC: U.S. Department of Health and Human Services. Retrieved from http://www.aoa.gov/ prof/statistics/profile/2003/2003profile.pdf

Baikie, E. (2002). The impact of dementia on marital relationships. Sexual and Relationship Therapy, 17, 289-299.

Bayliss, E. A., Steiner, J. F., Fernald, D. H., Crane, L. A., \& Main, D. S. (2003). Descriptions of barriers to self-care by persons with comorbid chronic illnesses. Annals of Family Medicine, 1, 15-21.

Berg, C. A., Meegan, S. P., \& Deviney, F. P. (1998). A social-contextual model of coping with everyday problems across the lifespan. International Journal of Behavioral Development, 22, 239-261.

Berg, C. A., \& Upchurch, R. (2007). A developmental-contextual model of couples coping with chronic illness across the adult life span. Psychological Bulletin, 133, 920-954.

Bodenmann, G. (2005). Dyadic coping and its significance for marital functioning. In T. A. Revenson, K. Kayser, \& G. Bodenmann (Eds.), Couples coping with stress: Emerging perspectives on dyadic coping (pp. 33-49). Washington, DC: American Psychological Association.

Boss, P. (2006). Resilience and health. In P. Boss (Ed.), Loss, trauma, and resilience: Therapeutic work with ambiguous loss (pp. 47-70). New York, NY: Norton.

Carstensen, L. L., Isaacowitz, D. M., \& Charles, S. T. (1999). Taking time seriously: A theory of socioemotional selectivity. American Psychologist, 54, 165-181.

Charmaz, K. (1983). The grounded theory method: An explication and interpretation. In R. M. Emerson (Ed.), Contemporary field research (pp. 109-126). Prospect Heights, IL: Waveland.

Corbin, J., \& Strauss, A. (1990). Grounded theory research: Procedures, canons and evaluative criteria. Qualitative Sociology, 13(1), $3-21$.

Coyne, J. C., Rohrbaugh, M. J., Shoham, V., Sonnega, J. S., Nicklas, J. M., \& Cranford, J. A. (2001). Prognostic importance of mari- 
tal quality for survival of congestive heart failure. American Journal of Cardiology, 88, $526-529$.

Daly, K. J. (2007). Qualitative methods for family studies and human development. Los Angeles, CA: Sage.

Denham, S. A., Manoogian, M. M., \& Schuster, L. (2007). Managing family support and dietary routines: Type 2 diabetes in rural Appalachian families. Families, Systems, \& Health, 25, 36-52.

Denz-Penhey, H., \& Murdoch, C. (2008). Personal resiliency: Serious diagnosis and prognosis with unexpected quality outcomes. Qualitative Health Research, 18, 391-404.

Fisher, L., Chesla, C. A., Bartz, R. J., Gillis, C., Skaff, M. A., Sabogal, F., ... Lutz, C. P. (1998). The family and type 2 diabetes: A framework for intervention. The Diabetes Educator, 24, 599-607.

Foxall, M. J., Kollasch, C., \& McDermott, S. (1989). Family stress and coping in rheumatoid arthritis. Arthritis Care and Research, 2, 114-121.

Funk, L. M., \& Stajduhar, K. I. (2009). Interviewing family caregivers: Implications of the caregiving context for the research interview. Qualitative Health Research, 19, 859867.

Geertz, C. (1988). Thick description: Toward an interpretive theory of culture. In P. Bohannan \& M. Glazer (Eds.), High points in anthropology (2nd ed., pp. 531-522). New York, NY: Basic Books.

Gilden, J. L., Hendryx, M., Casia, C., \& Singh, S. P. (1989). The effectiveness of diabetes education programs for older patients and their spouses. Journal of the American Geriatrics Society, 37, 1023-1030.

Gilgun, J. (2005). Qualitative research and family psychology. Journal of Family Psychology, 19, 40-50.

Goodwin, S. S. (2000). Couples' perceptions of wives' CFS symptoms, symptom change, and impact on the marital relationship. Issues in Mental Health Nursing, 21, 347-363.

Groth, T., Fehm-Wolfsdorf, G., \& Hahlweg, K. (2000). Basic research on the psychobiology of intimate relationships. In K. B. Schmaling \& T. G. Sher (Eds.), The psychology of couples and illness: Theory, research \& practice (pp. 13-42). Washington, DC: American Psychological Association.

Hoffman, C., Rice, D., \& Sung, H. Y. (1996). Persons with chronic conditions. Their prevalence and costs. The Journal of the American Medical Association, 276, 1473-1479.

Jang, Y., Poon, L. W., \& Martin, P. (2004). In- dividual differences in the effects of disease and disability on depressive symptoms: The role of age and subjective health. The International Journal of Aging \& Human Development, 59(2), 125-137.

Johnson, D. R., White, L., Edwards, J., \& Booth, A. (1986). Dimensions of marital quality: Towards methodological and conceptual refinement. Journal of Family Issues, 7, 31-50.

Kiecolt-Glaser, J. K., \& Newton, T. L. (2001). Marriage and health: His and hers. Psychological Bulletin, 127, 472-503.

Kistenmacher, B., \& Biglan, A. (2000). Decreasing the prevalence of marital conflict: A public health perspective for clinical research. In M. J. Dougher (Ed.), Clinical behavior analysis (pp. 245-70). Reno, NV: Context Press.

Kuijer, R. G., Ybema, J. F., Buunk, B. P., De Jong, G. M., Thijs-Boer, F., \& Sanderman, R. (2000). Active engagement, protective buffering, and overprotection: Three ways of giving support by intimate partners of patients with cancer. Journal of Social and Clinical Psychology, 19, 256-275.

Lawrence, R. C., Helmick, C. G., Arnett, F. C., Deyo, R. A., Felson, D. T., Giannini, E. H., . . . Wolfe, F. (1998). Estimates of arthritis and selected musculoskeletal disorders in the United States. Arthritis \& Rheumatism, 41, 778-799.

Löckenhoff, C. E., \& Carstensen, L. L. (2007). Aging, emotion, and health-related decision strategies: Motivational manipulations can reduce age differences. Psychology and Aging, 22, 134-146.

Manne, S. L., Norton, T. R., Ostroff, J. S., Winkel, G., Fox, K., \& Grana, G. (2007). Protective buffering and psychological distress among couples coping with breast cancer: The moderating role of relationship satisfaction. Journal of Family Psychology, 21, 380388.

Martire, L. M., Druley, J. A., Parris Stephens, M. A., \& Wojno, W. C. (2002). Negative reactions to received spousal care: Predictors and consequences of miscarried support. Health Psychology, 21, 167-176.

McCubbin, H. I., \& Patterson, J. M. (1982). Family adaptation to crisis. In H. I. McCubbin, A. E. Cauble, \& J. M. Patterson (Eds.), Family stress, coping, and social support (pp. 26-47). Springfield, IL: Thomas.

Merriam, S. B. (1998). Qualitative research and case study applications in education. San Francisco, CA: Jossey-Bass.

Miller, D., \& Brown, J. L. (2005). Marital interactions in the process of dietary change for 
type 2 diabetes. Journal of Nutrition Education and Behavior, 37(5), 226-234.

Pastor, P. N., Makuc, D. M., Reuben, C., \& Zia, H. (2002). Chartbook on trends in the health of Americans: Health, United States, 2002. Hyattsville, MD: National Center for Health Statistics.

Peyrot, M., McMurry, J. F., Jr., \& Hedges, R. (1988). Marital adjustment to adult diabetes: Interpersonal congruence and spouse satisfaction. Journal of Marriage and the Family, 50, 363-376.

Poon, L. W., Gueldner, S. H., \& Sprouse, B. M. (2003). Successful aging and adaptation with chronic disease. New York, NY: Springer.

QSR International Pty Ltd. (2006). NVivo qualitative data analysis software (Version 7) [Computer software]. Melbourne, Australia.

Revenson, T. A. (1994). Social support and marital coping with chronic illness. Annals of Behavioral Medicine, 16, 122-130.

Revenson, T. A., Schiaffino, K. M., Majerovitz, S. D., \& Gibofsky, A. (1991). Social support as a double-edged sword: The relation of positive and problematic support to depression among rheumatoid arthritis patients. Social Science and Medicine, 33, 807-813.

Roberto, K. A., Gigliotti, C. M., \& Husser, E. K. (2005). Older women's experiences with multiple health conditions: Daily challenges and care practices. Health Care for Women International, 26, 672-692.

Roberto, K. A., Gold, D. T., \& Yorgason, J. B. (2004). The influence of osteoporosis on the marital relationship of older couples. Journal of Applied Gerontology, 23, 443-456.

Rohrbaugh, M. J., Mehl, M. R., Shoham, V., Reilly, E. S., \& Ewy, G. A. (2008). Prognostic significance of spouse we talk in couples coping with heart failure. Journal of Consulting and Clinical Psychology, 76, 781-789.

Roper, S. O., \& Yorgason, J. B. (2009). Older adults with diabetes and osteoarthritis and their spouses: Effects of activity limitations, marital happiness, and social contacts on partners' daily mood. Family Relations, 58, $460-474$.

Sandberg, J. G. (2006). Interventions with family caregivers. In R. Crane \& E. Marshall
(Eds.), Handbook of families and health (pp. 407-422). New York, NY: Guilford Press.

Sandberg, J. G., Trief, P. M., Greenberg, R. P., Graff, K., \& Weinstock, R. S. (2006). "He said, she said": The impact of gender on spousal support in diabetes management. Journal of Couple and Relationship Therapy, 5(2), $23-42$.

Sandelowski, M. (2000). Whatever happened to qualitative description? Research in Nursing \& Health, 23, 334-340.

Schiaffino, K. M., \& Revenson, T. A. (1995). Relative contributions of spousal support and illness appraisals to depressed mood in arthritis patients. Arthritis Care and Research, 8(2), 80-87.

Trief, P. M., Sandberg, J., Greenberg, R. P., Graff, K., Castronova, N., Yoon, M., \& Weinstock, R. S. (2003). Describing support: A qualitative study of couples living with diabetes. Family, Systems and Health, 21, $57-67$.

Trief, P. M., Wade, M. J., Britton, K. D., \& Weinstock, R. S. (2002). A prospective analysis of marital relationship factors and quality of life in diabetes. Diabetes Care, 25, 1154-1158.

Walsh, F. (2002). A family resilience framework: Innovative practice applications. Family Relations, 51, 130-137.

Wray, L. A., Alwin, D. F., McCammon, R. J., Manning, T., \& Best, L. E. (2006). Social status, risky health behaviors, and diabetes in middle-aged and older adults. Journal of Gerontology: Social Sciences, 61B, S290S298.

Yorgason, J. B., Booth, A., \& Johnson, D. (2008). Health, disability, and marital quality: Is the association different for younger versus older cohorts? Research on Aging, 60, 623-648.

Yorgason, J. B., Piercy, F. P., \& Piercy, S. K. (2007). Acquired hearing impairment in older couple relationships: An exploration of couple resilience processes. Journal of Aging Studies, 21, 215-228.

Zautra, A. J., Burleson, M. H., Matt, K. S., Roth, S., \& Burrows, L. (1994). Interpersonal stress, depression, and disease activity in rheumatoid arthritis and osteoarthritis patients. Health Psychology, 13, 139-148. 